ARTIKEL PENELITIAN

\title{
Hubungan Indeks Massa Tubuh Yang Tinggi (Obesitas) Dengan Kejadian Flat Feet Pada Mahasiswa Fakultas Kedokteran UPN Veteran Jakarta Tahun Ajaran 2019/2020
}

\author{
Shifa Azzahra ${ }^{1}$, Diana Agustini $\mathbf{P}^{2}$, Mila Citrawati ${ }^{3}$ \\ ${ }^{1}$ Program Studi Kedokteran Program Sarjana, FK UPN "Veteran" Jakarta \\ ${ }^{2}$ Departemen Anatomi, FK UPN "Veteran" Jakarta \\ ${ }^{3}$ Departemen Fisiologi, FK UPN "Veteran" Jakarta \\ E-mail : shifa.azzahra25@gmail.com
}

\begin{abstract}
Abstrak: Flat feet adalah suatu kondisi yang ditandai dengan arkus kaki (arcus longitudinal medial) mendatar saat sedang menopang beban tubuh. Kasus kejadian flat feet masih belum diketahui dengan jelas karena belum ada konsensus klinis atau kriteria secara radiologis untuk menentukan flat feet. Salah satu faktor yang diketahui dapat menyebabkan flat feet adalah obesitas. Seseorang yang mengalami obesitas akan menyebabkan tekanan pada arkus kaki lebih tinggi dibandingkan orang yang memiliki indeks massa tubuh normal sehingga dapat menyebabkan arkus kaki mendatar. Mahasiswa Fakultas Kedokteran memiliki risiko yang tinggi terhadap obesitas karena kurangnya aktivitas fisik dan pola makan yang tidak teratur. Tujuan penelitian ini adalah untuk mengetahui hubungan indeks massa tubuh yang tinggi (obesitas) terhadap kejadian flat feet pada mahasiswa Fakultas Kedokteran UPN Veteran Jakarta. Metode penelitian ini menggunakan desain cross sectional dengan 99 mahasiswa Fakultas Kedokteran (laki-laki dan perempuan) sebagai subjek. Arkus kaki dinilai dengan foot print test dan IMT subjek diukur saat pengambilan data tinggi dan berat badan. Hasil penelitian ini menunjukkan terdapat hubungan yang signifikan antara IMT dan flatfeet pada mahasiswa Fakultas Kedokteran UPN Veteran Jakarta tahun ajaran 2019/2020 ( $\mathrm{p}=0,001)$.
\end{abstract}

Kata kunci: flat feet, mahasiswa kedokteran, indeks massa tubuh, obesitas.

\section{Correlation Between High Body Mass Index (Obesity) And Incidence Of Flat Feet In Medical Faculty Of Upn Veteran Jakarta Students In The 2019/2020 Academic Year}

\begin{abstract}
Flat feet is a condition characterized by flattening arch of the foot (medial longitudinal arcus) while supporting the body weight. The prevalence of flat feet is still not clearly known yet, because there is no clinical consensus or radiological criteria to determine flat feet. One factor that might cause a flat feet is obesity. An obese person will put a higher pressure on the arch of the foot compared with others that have a normal body mass index, so it will cause a flattening on arch of the foot. Medical Faculty students have high risk of obesity due to lack of physical activity and irregular eating pattern. The purpose of this study was to determine the relation of high body mass index (obesity) and the incidence of flat feet in Medical Faculty of UPN Veteran Jakarta students. This methodological research used cross sectional design with 99 students as subject. Foot arcs were assessed by a foot print test and BMI were calculated after measurement height and weight of subject. The results of this study indicated that there is a significant relation between body mass index and incidence of flat feet in Medical Faculty of UPN Veteran Jakarta students in the 2019/2020 academic year $(p=0.001)$.
\end{abstract}

Keywords: flat feet, medical student, body mass index, obesity. 


\section{PENDAHULUAN}

Obesitas dapat diartikan sebagai penimbunan abnormal jaringan lemak berlebih di bawah kulit. Penyebab obesitas adalah masukan makanan yang jumlahnya lebih besar daripada penggunaannya sebagai energi bagi tubuh. ${ }^{1}$

Penyebab obesitas dapat disederhanakan menjadi dua hal yakni, terlalu banyak masukan makanan dan terlalu sedikit keluaran energi atau aktivitas. ${ }^{2}$ Menurut Kementrian Kesehatan RI (Kemenkes RI) 2018, tingkat obesitas pada orang dewasa di Indonesia meningkat menjadi 21,8\%. Prevalensi obesitas lebih tinggi di daerah perkotaan dibanding dengan pedesaan, dan berdasarkan jenis kelamin, prevalensi obesitas pada perempuan lebih tinggi dibandingkan laki- laki. ${ }^{3}$

Obesitas merupakan penyebab dan faktor risiko dari berbagai penyakit yang dapat mengakibatkan perubahan fisiologis maupun anatomis. Salah satu risiko kelainan anatomis yang diduga akan timbul karena obesitas adalah flat feet. ${ }^{4}$ Flat feet atau pes planus merupakan kondisi orthopedik klinis yaitu arcus longitudinal medial tidak tampak atau rata dan area tersebut tertimbun jaringan lemak. Kebanyakan flat feet diturunkan secara genetik sehingga arkus tidak terbentuk sampai dewasa.
Normalnya arkus terbentuk dari 5 tahun pertama dengan rentang usia 2-6 tahun. Masa puncak untuk pembentukan arkus tersebut adalah usia 6 tahun. ${ }^{5}$ Jika kondisi ini terjadi pada usia dewasa, tentu akan menyebabkan berbagai macam gangguan. Kelainan postur kaki (flat feet) yang dalam jangka panjang dapat menyebabkan nyeri pada telapak kaki, lutut dan pergelangan kaki, selain itu juga dapat menyebabkan trauma akut yang berulang hingga terjadinya deformitas pada kaki. $^{6}$

Walaupun demikian, penelitian mengenai data dan hubungan antara flat feet dengan obesitas masih terbatas. Penelitian yang membahas flat feet terkait kasus kejadian atau faktor risikonya sebagian besar membahas pada populasi anak- anak dan remaja sedangkan pada dewasa muda masih sangat terbatas. Hal ini menyebabkan kurangnya data atau informasi yang jelas mengenai kasus kejadian maupun faktor risiko flat feet di Indonesia.

\section{METODE}

\section{Desain Penelitian}

Jenis penelitian yang digunakan pada penelitian ini adalah penelitian analitik observasional yaitu peneliti hanya melakukan observasi atas perubahan alamiah yang terjadi tanpa melakukan intervensi pada responden. ${ }^{7}$ 
Desain penelitian yang digunakan adalah cross sectional. Penelitian ini dilakukan untuk mengetahui hubungan yang bermakna antara indeks massa tubuh yang tinggi (obesitas) dengan kejadian flat feet pada mahasiswa Fakultas Kedokteran UPN Veteran Jakarta tahun ajaran 2019/2020.

\section{Populasi dan Sampel}

Populasi pada penelitian ini adalah mahasiswa dan mahasiswi Fakultas Kedokteran UPN Veteran Jakarta program studi pendidikan dokter tahun ajaran 2019/2020.

Sampel yang digunakan dalam penelitian ini adalah Mahasiswa/i yang berusia $\geq 18$ tahun, tidak memiliki riwayat trauma atau riwayat operasi pada tungkai bagian bawah, tidak sedang mengalami inflamasi pada bagian telapak kaki, tidak terdiagnosis penyakit muskuloskeletal, dan tidak memiliki riwayat kelainan kongenital pada sistem muskuloskeletal.

\section{Pengambilan Sampel}

Pengambilan sampel pada penelitian ini menggunakan teknik simple random sampling, yaitu setiap anggota populasi memiliki kesempatan yang sama untuk diseleksi sebagai sampel.

\section{Pengumpulan Data}

Membagikan kuesioner yang berisi informed consent dan data karakteristik responden lalu memilih responden secara acak sesuai dengan kriteria yang ditetapkan. Selanjutnya mengukur tinggi dan berat badan responden dengan timbangan digital yang sudah dikalibrasi dan pengukur tinggi badan. Lalu mengukur indeks massa tubuh responden dengan cara berat badan (dalam $\mathrm{kg}$ ) dibagikan dengan tinggi badan (dalam m) kuadrat.

Mengukur derajat flat feet dengan menggunakan metode foot print yaitu dengan cara kaki responden yang sudah tidak menggunakan alas kaki diletakkan pada baki plastik yang berisi cairan berwarna dan ditempelkan di kertas polos dengan posisi berdiri. Setelah itu melakukan perhitungan pengukuran telapak kaki yang sudah tercetak pada kertas putih polos. Aksis kaki diperoleh dengan menarik garis dari pertengahan tumit belakang sampai ke bagian tengah jari kedua.

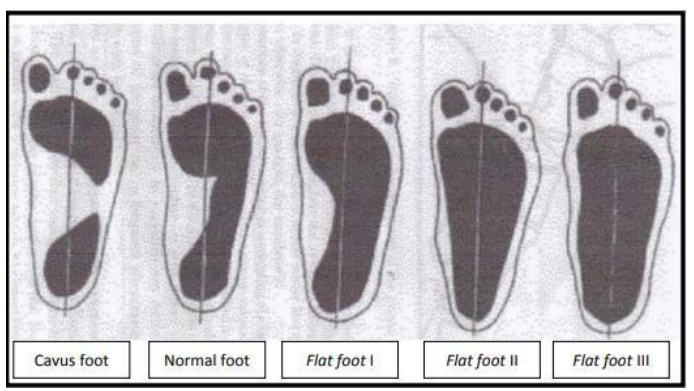

Gambar 1 Klasifikasi arkus kaki. ${ }^{8}$ 


\section{HASIL}

Hasil yang didapat pada penelitian ini berasal dari data primer mahasiswa maupun mahasiswi Fakultas Kedokteran tahun ajaran 2019/2020. Sampel penelitian ini berjumlah sebanyak 99 orang. Sebelumnya pemilihan sampel sudah diacak secara random dan responden menyetujui untuk dilakukan pemeriksaan tinggi dan berat badan serta footprint test melalui informed consent yang diberikan saat sebelum pemeriksaan. Analisis univariat untuk karakteristik responden penelitian dapat dilihat pada Tabel 1.

\section{Tabel 1 Karakteristik Responden}

\begin{tabular}{llll}
\hline Variabel & Kategori & $\begin{array}{l}\text { Jumlah } \\
(\mathbf{n})\end{array}$ & $\begin{array}{l}\text { Presentase } \\
(\%)\end{array}$ \\
\hline Jenis & Perempuan & 66 & 66,7 \\
Kelamin & Laki-laki & 33 & 33,3 \\
Usia & 18 tahun & 16 & 16,2 \\
& 19 tahun & 26 & 26,3 \\
& 20 tahun & 32 & 32,3 \\
& 21 tahun & 22 & 22,2 \\
& 22 tahun & 3 & 3,0 \\
IMT & Tidak & 41 & 41,4 \\
& Obesitas & & \\
& Obesitas 1 & 38 & 38,4 \\
& Obesitas 2 & 20 & 20,2 \\
Krkus & Normal & 48 & 48,5 \\
& Flat feet 1 & 32 & 32,3 \\
& Flat feet 2 & 12 & 12,1 \\
& Flat feet 3 & 7 & 7,1 \\
\hline
\end{tabular}

Dari data yang diperoleh peneliti, sampel data mahasiswa FK UPNVJ tahun ajaran 2019/2020 menunjukkan presentase mahasiswa yang paling banyak didapatkan berdasarkan kelompok jenis kelamin adalah kelompok perempuan sebanyak 66 orang $(66,7 \%)$ sedangkan pada kelompok laki- laki sebanyak 33 orang $(33,3 \%)$. Jika dibandingkan dengan penelitian sebelumnya, hasil penelitian Shree tahun 2018 di India pada mahasiswa departemen ilmu kesehatan dan keperawatan menunjukkan bahwa kelompok jenis kelamin terbanyak adalah perempuan yaitu sebanyak $61,76 \%$ dan lakilaki sebanyak 38,24\%. ${ }^{10}$ Pada penelitian Wijaya pada tahun 2017 pada mahasiswa Fakultas kedokteran didapatkan sampel perempuan sebanyak $66,4 \%$ dan laki-laki sebanyak 33,6\%. ${ }^{12}$ Pada penelitian Chougala et al pada tahun 2015 di India pada mahasiswa fisioterapi usia 18-25 tahun didapatkan sampel perempuan sebanyak 182 responden dan laki-laki sebanyak 46 responden. $^{14}$ Karakteristik sampel jenis kelamin pada penelitian-penelitian tersebut tidak jauh berbeda dengan sampel yang didapat pada mahasiswa Fakultas Kedokteran UPN "Veteran" Jakarta tahun ajaran 2019/2020 yaitu perbandingan antara sampel laki-laki dan perempuan tidak seimbang dan lebih banyak pada sampel perempuan. Hal ini dimungkinkan karena populasi perempuan dibandingkan dengan 
populasi laki-laki memang lebih banyak pada target populasi yang diteliti.

Pada kelompok usia didapatkan paling banyak pada responden yang berusia 20 tahun yaitu sebanyak 32 responden. Hal ini sesuai dengan penelitian Arthi (2018) yaitu usia rata-rata peserta adalah 20 tahun. ${ }^{18}$

Pada kelompok indeks massa tubuh didapatkan presentase mahasiswa yang paling banyak didapatkan berdasarkan kelompok indeks massa tubuh adalah kelompok obesitas dimana didapatkan sebanyak 58 responden $(58,6 \%)$ yang mengalami obesitas dan 41 responden $(41,4 \%)$ yang tidak mengalami obesitas. Hal tersebut tidak sesuai dengan epidemiologi obesitas pada analisis Riskesdas tahun 2018 yang berkisar di angka $31 \%$ dari populasi. Angka kejadian obesitas pada penelitian ini terlampau tinggi. Menurut Sherwood (2012), Obesitas disebabkan oleh banyak faktor, antara lain genetik, lingkungan, psikis, kesehatan, obat-obatan, perkembangan, asupan energi dan aktivitas fisik. ${ }^{15}$ Pada penelitian ini dimungkinkan penyebab tingginya angka obesitas pada mahasiswa FK UPN "Veteran" Jakarta tahun ajaran 2019/2020 karena faktorfaktor mendasar yang tidak tersebar secara merata pada FK UPN "Veteran" Jakarta. Seperti pendapat Chalidzar (2019), yang menyatakan bahwa aktivitas fisik yang kurang pada mahasiswa Fakultas Kedokteran dapat meningkatkan risiko terjadinya obesitas. ${ }^{16}$ Hal ini mencerminkan bahwa mahasiswa Fakultas Kedokteran mempunyai risiko yang tinggi untuk mengalami obesitas dibandingkan populasi umum.

Pada kelompok arkus kaki yang dikelompokkan menjadi arkus kaki normal dan flat feet, didapatkan kelompok arkus kaki flat feet lebih banyak dibandingkan dengan arkus kaki normal. Hal tersebut tidak sesuai dengan epidemiologi flat feet yang berkisar hanya $20 \%$ dari populasi. ${ }^{17}$ Hal ini mungkin disebabkan karena pada penelitian ini lebih banyak responden yang memiliki indeks massa tubuh obesitas sehingga didapatkan lebih banyak responden yang memiliki arkus kaki flat feet. Menurut Lowth (2016), penyebab terbanyak dari flat feet adalah kelainan muskuloskeletal lain, trauma dan obesitas. ${ }^{17}$ Analisis bivariat dilakukan dengan uji statistik fisher dan untuk hasilnya dapat dilihat pada Tabel 2. 
Tabel 2 Hubungan IMT dengan Arkus Kaki

\begin{tabular}{|c|c|c|c|c|c|c|c|c|c|c|c|}
\hline \multirow{3}{*}{ IMT } & & & \multicolumn{4}{|c|}{ Arkus Kaki } & & & \multicolumn{2}{|c|}{ Total } & \multirow[t]{3}{*}{ Nilai p } \\
\hline & \multicolumn{2}{|c|}{ Normal } & \multicolumn{2}{|c|}{$\mathrm{FF}^{\mathbf{0}} \mathbf{1}$} & \multicolumn{2}{|c|}{$\mathrm{FF}^{0} 2$} & \multicolumn{2}{|c|}{$\mathbf{F F}^{\mathbf{0} 3}$} & & & \\
\hline & n & $\%$ & n & $\%$ & $\mathbf{n}$ & $\%$ & n & $\%$ & $\mathbf{n}$ & $\%$ & \\
\hline $\begin{array}{c}\text { Tidak } \\
\text { Obesitas }\end{array}$ & 37 & 37,4 & 3 & 3 & 1 & 1 & 0 & 0 & 41 & 41,4 & \\
\hline Obesitas 1 & 11 & 11,1 & 17 & 17,2 & 6 & 6,1 & 4 & 4 & 38 & 38,4 & 0.001 \\
\hline Obesitas 2 & 0 & 0 & 12 & 12,1 & 5 & 5,1 & 3 & 3 & 20 & 20,2 & \\
\hline Total & 48 & 48,5 & 32 & 32,3 & 12 & 12,1 & 7 & 7,1 & 99 & 100 & \\
\hline
\end{tabular}

Berdasarkan Tabel 2, dapat disimpulkan bahwa kejadian flat feet lebih banyak pada responden yang mengalami obesitas derajat 1 dan 2 dibandingkan dengan responden yang tidak mengalami obesitas. Bahkan, pada responden dengan obesitas derajat 2 didapatkan seluruh responden memiliki arkus kaki flatfeet. Hal ini mungkin disebabkan karena obesitas dapat membuat tekanan pada arkus telapak kaki menjadi sangat tinggi sehingga menyebabkan arkus kaki mendatar. ${ }^{9}$ Flat feet juga dapat ditemukan pada seseorang yang tidak mengalami obesitas walaupun hanya sebagian kecil seperti pada penelitian ini didapatkan hanya sekitar $4 \%$ responden dengan indeks massa tubuh normal yang memiliki arkus kaki flat feet. Hal tersebut bisa disebabkan karena faktor genetik atau trauma yang menyebabkan perubahan posisi jaringan ikat atau tulang yang menyusun arkus longitudinal medial.

Berdasarkan hasil analisis dengan uji statistik fisher didapatkan nilai p sebesar $0,001 \quad(\mathrm{p}<0,05)$ yang menunjukkan hubungan yang bermakna antara indeks massa tubuh yang tinggi (obesitas) dengan kejadian flat feet pada mahasiswa Fakultas Kedokteran UPN "Veteran" Jakarta tahun ajaran 2019/2020. Hasil penelitian ini sesuai dengan penelitian yang dilakukan oleh Shree $(2018)^{10}$ di India bahwa terdapat hubungan yang bermakna antara obesitas dengan flat feet. Penelitian yang dilakukan oleh Mickle (2006) ${ }^{11}$ pada 95 anak dari 10 sekolah yang dipilih secara acak di New South Wales, Australia juga didapatkan hasil yang sama. Dalam penelitian Mickle yang dianalisis dengan menggunakan independent t-test, didapatkan anak yang mengalami obesitas atau overweight memiliki tinggi arkus yang lebih rendah daripada yang dimiliki oleh anak normal $(p=0.04)$. Pada penelitian tersebut juga disimpulkan bahwa anak dengan obesitas atau overweight akan memberikan tekanan 
E-ISSN: 2614-5219

yang lebih besar pada arkus longitudinal medial yang berhubungan dengan semakin rendahnya arkus longitudinal medial tersebut.

Namun penelitian ini tidak sesuai dengan penelitian yang dilakukan oleh Wijaya (2015) ${ }^{12}$ pada mahasiswa program studi kedokteran dan profesi dokter FKIK UIN Syarif Hidayatullah Jakarta. Penelitian tersebut didapatkan menggunakan uji statistik chi-square dengan hasil tidak terdapat hubungan antara indeks massa tubuh dengan flexible flat foot tetapi mahasiswa yang memiliki Indeks massa tubuh obesitas lebih berisiko 0,679 kali untuk mengalami flexible flat foot dibandingkan dengan mahasiswa yang memiliki indeks massa tubuh normal. Hasil penelitian ini juga tidak sesuai dengan penelitian yang dilakukan oleh Hajirezaei dkk di Iran (2017). ${ }^{13}$ Penelitian tersebut bertujuan untuk mengetahui hubungan antara flat feet dan pes cavus dengan indeks massa tubuh pada mahasiswi dan didapatkan hasil bahwa tidak terdapat hubungan antara flat feet dan pes cavus dengan indeks massa tubuh pada mahasiswi Universitas Mazandaran. Pada penelitianpenelitian tersebut, variabel responden yang memiliki indeks massa tubuh obesitas dan arkus kaki flat feet hanya sedikit. Hal ini mungkin disebabkan karena variabel obesitas dan flat feet pada populasi target penelitian tersebut memang hanya sedikit sehingga pada penelitian tersebut bukti yang didapatkan kurang kuat untuk menggambarkan hubungan antara variabelvariabel yang diteliti.

\section{KESIMPULAN}

Berdasarkan hasil penelitian ini, dapat disimpulkan bahwa terdapat hubungan yang signifikan antara indeks massa tubuh yang tinggi (obesitas) dengan kejadian flat feet pada mahasiswa Fakultas Kedokteran UPN "Veteran" Jakarta tahun ajaran 2019/2020 dengan nilai $\mathrm{p}$ sebesar 0,001 .

\section{DAFTAR PUSTAKA}

1. Guyton, A., \& Hall, J. Buku Ajar Fisiologi Kedokteran Edisi 11. Jakarta: EGC; 2008.

2. Farida. Impact of Obesity and Body Fat Distribution on Pulmonary Function of Egyptian Children. Egyptian Journal of Bronchology. 2009;3:49-58.

https://www.researchgate.net/publication/2 68404708_Impact_of_Obesity_and_Body_ Fat_Distribution_on_Pulmonary_Function_ of_Egyptian_Children

3. Kemenkes RI. Riset Kesehatan Dasar. Kementrian Kesehatan, Pemerintah RI, Jakarta. 2018.

4. Sahabuddin, H. Hubungan Flat Foot dengan Keseimbangan Dinamis pada Murid TK 
E-ISSN: 2614-5219

Sulawesi Kota Makassar. Makassar: Universitas Hassanudin; 2016.

http://repository.unhas.ac.id/bitstream/han dle/123456789/18650/SKRIPSI.pdf?sequ ence $=1$

5. Azar, F. M., Canale, S. T., \& Beaty, J. H. Campbell's Operative Orthopaedics. Elsevier Health Sciences; 2012.

6. Harris, E. J., Vanore, J. V., Thomas, J. L., Kravitz, S. R., Mendelson, S. A., Mendicino, R. W. Diagnosis and Treatment of Pediatric Flat Foot. American College of Foot and Ankle Surgeons. 2004;43:341-373. https://www.jfas.org/article/S10672516(04)00460-0/abstract

7. Sastroasmoro, S., \& Ismael, S. Dasar-dasar Metodologi Penelitian Klinis. Edisi ke-4. Jakarta: Sagung Seto; 2011.

8. Idris, F. H. Filogeni dan Ontogeni Lengkung Kaki Manusia. Dalam Majalah Kedokteran Indonesia, Departemen Kedokteran Fisik dan Rehabilitasi Medik, Fakultas Kedokteran Universitas Indonesia/Rumah Sakit Dr. Cipto Mangunkusumo, Jakarta. 2010;60(2):74-80.

https://adoc.tips/kaki-manusia-filogeni-

dan-ontogeni-lengkung-tinjauanpustaku.html

9. Chang, J. Prevalence of Flexible Flatfoot in Taiwanese School-Aged Children in Relation to Obesity, Gender, and Age. Eur J Peditr. 2010;169(4):447-452. https://pubmed.ncbi.nlm.nih.gov/1975673 2/

10. Shree, S. Does Obesity Cause Flat Foot?. Journal of Obesity \& Therapeutics. 2018;2. https://www.researchgate.net/publication/ 327883322_Does_Obesity_Cause_Flat_F oot

11. Mickle, K. J. Overweight and Obese Preschool Children: Are Their Feet Fat?. 2006;14(11):1949-1953

http://www.ncbi.nlm.nih.gov/pubmed/1713 5610

12. Wijaya, M. A. Hubungan Indeks Massa Tubuh terhadap Flexible Flat Foot pada Mahasiswa dan Mahasiswi Program Studi Kedokteran dan Profesi Dokter FKIK UIN Syarif Hidayatullah Jakarta. Jakarta: FKIK UIN Syarif Hidayatullah Jakarta; 2015. http://repository.uinjkt.ac.id/dspace/bitstre am/123456789/37287/1/M.\%20ADE\%20 WIJAYA-FKIK.pdf

13. Hajirezaei, B., Mirzaei, S., \& Khezri, A. The relationship between flat feet and cavus foot with body mass index in girl studens. International Journal of Applied Exercise Physiology. 2017;6(3):15-22.

http://www.ijaep.com/index.php/IJAE/arti cle/view/184

14. Chougala, A., Phanse, V., Khanna, E., \& Panda, S. Screening of Body Mass Index and Functional Flatfoot in Adult: An Observational Study. International Journal 
of Physiotherapy and Research. 2015;3(3):1037-1041

https://www.researchgate.net/publication/ 278038768 screening of body mass ind $\underline{\text { ex_and_functional_flatfoot_in_adult_an }}$ observational_study

15. Sherwood, L. Fisiologi Manusia dari Sel ke Sistem Edisi 6. Jakarta: EGC; 2012.

16. Chalidzar, F., Arnelis, Elliyanti, A. Pengaruh aktivitas fisik menggunakan YMCA Step Test terhadap perubahan kadar gula darah sewaktu pada mahasiswa FK Universitas Andalas. 2019;9(1S).

http://jurnal.fk.unand.ac.id/index.php/jka/ar $\underline{\text { ticle/view/1154 }}$

17. Lowth, M. Pes Planus The arches of the foot Types of pes planus Aetiology of pes planus. Pes planus in children. Orthop. Sport. Med.; 2016. p.1- 12.

18. Arthi, G., Sadeesh, T., \& Raghuram, K. Effect of Height, Weight, and BMI on Foot Postures of Young Adult Individuals. Journal of Clinical and Diagnostic Research. 2018;12.

https://www.researchgate.net/publication/ 327223985 Effect of Height Weight an d_BMI_on_Foot_Postures_of_Young_Ad ult_Individuals 